\title{
La intimidad de una ausencia: sobre la poesía de Jorge Leonidas Escudero
}

\author{
The intimacy of an absence: about the poetry of Jorge Leonidas \\ Escudero
}

\author{
Marisa Río \\ Colegio Santo Tomás de Aquino, Argentina \\ marisaritario@yahoo.com.ar \\ Laura Raso \\ Universidad Nacional de San Juan, Argentina \\ lauraraso@hotmail.com \\ Recibido: 05/05/2021. Aceptado: 10/06/2021.
}

\begin{abstract}
Resumen
Dice Blanchot que aquello que habla en un escritor es el hecho de que "ya no es él mismo, ya no es nadie" (1969: 26). En dos libros de poemas de Jorge Leonidas Escudero -Dicho en mí (2008) y Cantos del acechante (1995)-, esa experiencia vital se articula, a nuestro criterio, alrededor de cuatro temas: la creación poética, la muerte, la búsqueda de la verdad o el sentido de la vida, y el amor. En este artículo analizamos dos libros que representan dos instancias vitales del poeta: la madurez y la vejez. Creemos que en este recorrido puede leerse un sutil viraje textualizado a través de metáforas que analizaremos a través de la teoría de Lakoff y Johnson (1991).
\end{abstract}

Palabras clave: Jorge Leonidas Escudero; poesía argentina; metáfora

\begin{abstract}
Blanchot says what speaks in a writer is the fact that "he is no loger himself, he insn't anyone any more". In two poetry books by Jorge Leonidas Escudero -Dicho en mi (2008) y Cantos del acechante (1995)-, this vital experience appears in relationship with four subjects: the poetic creation, death, the search of truth or sense of life, and love. In this article we analyze two books that represent two vital instances of the poet: maturity and
\end{abstract}


old age. We believe that in this journey a subtle textualized vital turn can be read through metaphors that we will analyze through the theory of Lakoff and Johnson (1991).

Keywords: Jorge Leonidas Escudero; Argentine poetry; metaphor

\section{La prisión del canto}

Si escribir es descubrir lo interminable, el escritor que penetra esa región no se adelanta hacia lo universal. No va hacia un mundo más seguro, más hermoso, mejor justificado, donde todo se ordenaría según la claridad de un día justo. No descubre el hermoso lenguaje que habla honorablemente para todos. Lo que en él habla, es que de una u otra manera ya no es él mismo, ya no es nadie.

Maurice Blanchot. El espacio literario.

Si como dice Blanchot, lo que en el poeta habla es algo diferente de él mismo, entonces entendemos el por qué del título Dicho en mí, del poeta sanjuanino Jorge Leonidas Escudero. Tal vez expresa aquello que habla en el escritor, o lo que, por su ausencia, por lo inefable de la experiencia humana, solo está reservado a la intimidad huérfana de palabras.

En este libro de Escudero, esa experiencia vital se articula, a nuestro criterio, alrededor de cuatro temas que aparecen como dominio "meta" de las construcciones metafóricas: la creación poética, la muerte, la búsqueda de la verdad o el sentido de la vida, y el amor.

Siguiendo a Lakoff y Johnson, analizaremos las metáforas a las que recurre el escritor para hablar de los temas mencionados, teniendo en cuenta que, para estos estudiosos, la metáfora "impregna la vida cotidiana, no solamente el lenguaje, sino también el pensamiento y la acción. Nuestro sistema conceptual ordinario, en términos del cual pensamos y actuamos, es fundamentalmente de naturaleza metafórica" (Lakoff y Johnson, 1991: 39). 


\section{Oficio de suerte milagrera. La creación poética}

A pesar de que el poema "Catitero" no pertenece al libro que configura nuestro corpus de análisis, lo hemos elegido para acercarnos a la lírica del escritor sanjuanino, en tanto que, creemos, nos permite leer en él una especie de ars poetica del autor.

Es conocida la asociación del pájaro (portador del canto) con la inspiración poética. Se alude, en este caso, a una metáfora de tipo estructural en la que "un concepto está estructurado metafóricamente en términos de otro" (Lakoff y Johnson, 1991: 50). Es decir, la metáfora se construye de este modo: el dominio fuente es "lo alado" y su correlato cognitivo (dominio meta) es la poesía, la inspiración poética.

En el caso de Escudero, la idea de la inspiración poética, dada su cercanía con lo coloquial y lo cotidiano, toma la forma de "catitas", "mariposas" y, en un sentido negativo, "moscas negras".

En el poema "Catitero", el poeta se adjudica el oficio "de suerte milagrera" de vender catitas. De algún modo, las catitas rebajan la noción de "pájaro", son aves "brutas" y "empedernidas". Frente al pájaro, que por su canto se relaciona con la poesía, las catas son aves que imitan la voz humana: "pájaros verdes / que nunca cantarán como es debido / precisamente porque son catitas" (Escudero, 1978: 11).

Por eso, la condición de "cata" por un lado remite a una especie de degradación del canto-poesía y por otro lado, se re-significa en lo regional: la cotorrita argentina o "cata" es un nombre que se utiliza en ciertas regiones de Argentina. El poeta lo dice: "Nombres de aquí no más, de la otra esquina, / que no alcanzan bondad extraterrena" (11).

En esta poesía, el tono afectivo general es el de impotencia: la palabra poética es esquiva, se convierte en "bulla", se "atora y se niega", se traduce en ruido que se pierde en el "cielo del paladar" y no es inspiración que se dicta al poeta, no sale "como debe salir, desde el pecho arriba" (11). 
Por otro lado, como se ha dicho sobre la obra de Escudero, la suya es una pretensión de cantar desde lo cotidiano, desde su tierra ${ }^{1}$, es un oficio "por aspirar palabra luminosa, / por querer recogerla desde abajo / y presentarla arriba de otro modo" (11). Así, la metaforización (de tipo orientacional) adquiere otro sentido: "abajo" es la tierra, lo propio, el cuerpo, mientras que "arriba" alude a la poesía, lo espiritual.

En el poema "Soliloquiar" de Dicho en mí (Escudero, 2008: 9), el yo lírico es también el sujeto paciente ${ }^{2}$ de un diálogo con la soledad, que se burla de sus intenciones poéticas. La soledad es, entonces, la interlocutora que persigue e interpela al poeta. Pero es también el desdoblamiento del sujeto que se defiende ante el desaliento, por eso este fingido diálogo no lo es, es un soliloquio del poeta desesperanzado. La soledad, como personificación de esa interlocutora (y desdoblamiento del yo), constituye una metáfora ontológica que "nos permite elegir partes de nuestra experiencia y tratarlas como entidades discretas o sustancias de un tipo uniforme" (Lakoff y Johnson, 1991: 63).

Por otro lado, se repite en este poema la metáfora estructural de "lo alado" como inspiración poética: escribir poesía es intentar cazar una mariposa y ponerla en un verso. Frente a esta pretensión, la impotencia, el desaliento del poeta, personificado en la "soledá", rebaja la poesía del escritor a "moscas negras". Sin embargo, el poeta alega argumentando que "alguna mariposita garré" y que lo feo, la poesía no lograda, debe dejarse de lado.

Dice Blanchot: "El poema -la literatura- parece ligado a una palabra que no puede interrumpirse, porque no habla: es. El poema no es esa palabra, es comienzo, y la palabra no comienza nunca, pero siempre dice otra vez y

1 Para Álvaro Urrutia (2008), la poesía de Escudero "es sumamente respetuosa del tiempo que el paisaje sanjuanino da a su realidad. [...] Nuestro poeta es un hombre de experiencia americana y por ello mismo, su poesía, nos acerca a la compresión de nuestro ser. Escudero es un hombre parte de la cordillera sanjuanina, caminador de esa abrumadora y hostil inmensidad". Para Beatriz Mosert de Flores, el poeta es "puente dialógico de la cuyanidad como expresión de andinidad" (cit. en Robledo, 2010).

2 Utilizamos como metodología de análisis algunas de las precisiones que hace Zonana (2008) sobre la enunciación lírica y el tipo de pacto que la lírica promueve con el lector. 
siempre vuelve a comenzar" (1969: 31). La esencialidad de la palabra poética que es, y la impotencia del poeta por no encontrarla, deviene en Escudero en un oficio de vendedor de catitas, que traquetea la prisión del canto, o en un perseguidor de mariposas para alojarlas en un verso.

\section{Eros, thánatos: la muerte}

No es raro que en un libro de poesías de un hombre de 88 años, la muerte sea una preocupación constante, la certeza de lo que espera, "casi en la puerta de nuestra total ausencia" (Escudero, 2008: 15).

En el volumen Dicho en mí, el tópico de la muerte se repite. "Todavía", "La comparanza", "El pájaro sibilante", "Mirada al abismo", "La visita", "Palabra de casamiento", "Toc, toc, toc", "La seguidora", configuran esta imagen de la muerte a través de distintas estrategias.

En "Palabra de casamiento", la metáfora de la muerte se construye como una amante celosa que espera el cumplimiento de la palabra, dada por el poeta, de casarse con ella. En este caso, la personificación (metáfora ontológica, como hemos dicho) de la oposición vida/muerte se corporiza en dos mujeres que podríamos nombrar como mujer 1 y mujer 2 . El poeta puede seguir vivo mientras, como amante, siga escribiéndole versos (de amor, suponemos) a la vida.

La pulsión de vida (eros) se manifiesta a través del deseo (en el sentido psicoanalítico del término), que como tal es siempre diferido: "las ganas / de ir al mercado a comprar migajas / y ver que me falta plata / para matar el hambre infinita" (Escudero, 2008: 47), que es también la poesía como búsqueda del sentido de la vida.

En este caso, la metáfora de la vida y la muerte como amantes, recurrente en la literatura, se reviste de cierto humor: el poeta pide una especie de prórroga a la muerte, que espere a que él enviude de la vida. El sujeto lírico y sujeto paciente se convierte entonces en un hombre dividido entre la pulsión de vida y la pulsión de muerte, eros y thánatos. 
Sin embargo, es significativo que la tercera persona de la que se habla sea la muerte (nombrada en este poema como "la Nada") y que la vida sea solamente una alusión en relación con la otra que obligaría al poeta a cumplir su palabra de casamiento.

En la metáfora sobre la cual se construye el poema "El pájaro sibilante", el ave no remite solo al canto del poeta, sino que es también el anticipo de la muerte: "éste es un sibilante / pájaro cantor que desde adentro / anuncia mi involuntario retiro / de bares, viejos amigos / y últimas ilusiones" (23). Contraponiéndose al poema "Palabra de casamiento", la muerte no aparece aquí como amante: la forma afectiva general es la del miedo a la muerte. No hay, como en el otro poema, la metaforización de la relación muerte- poeta como amorosa, sino el terror de la enfermedad que anticipa el final: "Es horroroso / oír en alta noche la voz fúnebre / dese pájaro burlesco que stá organizando / mi despedida final con una rechifla" (47).

\section{La sombra de un sueño: la búsqueda del sentido vital}

Unida, muchas veces, al tópico de la inspiración poética, la búsqueda del sentido vital y de la verdad aparece en algunos poemas de este volumen: "En la mar tenebrosa", "Ómnibus sabio", "También en tren", "Acrobacia", "A cielo abierto", "Noche de perro", "Casi no", "Non aurum vulgi".

En el poema "En la mar tenebrosa", aparece un alocutario que en realidad encubre el desdoblamiento del yo lírico. El poeta se dirige a sí mismo en tono de recriminación por "seguir el canto de las sirenas y el vuelo de los pájaros" (Escudero, 2008: 11). Escudero utiliza, como vemos, el recurso de intertextualidad ("el canto de sirenas") y la metáfora- símbolo del "vuelo de los pájaros".

En cuanto a la intertextualidad con el texto de Homero, como señala Pérez Rioja en su Diccionario de símbolos y mitos, las sirenas "son un símbolo de la seducción atrayente y peligrosa, [...] de la imaginación pervertida y atraída por los instintos; y son también símbolo del deseo y de las tentaciones que obstaculizan la visión del espíritu" (1997: 388). Esta 
condición de tentación y engaño está también en "las ciudades de oro", las "perlas de Cipango", la creencia de estar yendo "hacia la luz", que textualizan los sueños ilusorios del ser humano.

En cuanto al vuelo de los pájaros, puede, como dijimos, remitir al dominio (metacognitivo) de la poesía, pero también, por la fugacidad del vuelo, a lo que es provisorio y efímero.

El grado de objetivización de las emociones del yo lírico, a partir del desdoblamiento del yo (esa segunda persona a la que el poeta habla), que es también el sujeto paciente de la composición, se ahonda en las dos últimas estrofas cuando ese sujeto paciente se convierte en una tercera persona de la que se habla: "Mírenlo, ahí va" (Escudero, 2008: 11). Lo individual se generaliza: la condición del yo como poeta se convierte en la condición de todos los poetas o, más aún, de todos los humanos.

El acto ilocutorio del poema oscila, por este juego de voces, entre una recriminación a sí mismo ("A otro mar podrías que no fuera a ése/ donde es desbordarse de uno mismo ir / a jamás de los jamases") y un consejo ("Quedate, no avancés"), mientras que, las preguntas retóricas de la estrofa final cristalizan la forma afectiva de angustia ante la falta de sentido de la vida: "¿Ha descubierto qué? / ¿La inutilidad de la existencia / y ahora corre tras la sombra de un sueño?" (11).

La metáfora de la vida como viaje es el motivo de "Ómnibus sabio". Se trata nuevamente de una metáfora de tipo estructural. La búsqueda de una certeza, de un sentido, se presenta como un intento: "sólo intentar es / calles que se fugan, salidas / hacia más allá de allá de allá.". Es, como decíamos antes, el deseo constitutivamente diferido, iconizado por la construcción "más allá de allá de allá" (29).

Nos parece significativo que el recorrido de ese "ómnibus sabio" tenga como marco espacial el paisaje rural: "Se asoman a la ruta asfaltada / esas calles de tierra y me gritan quedate, / encontrarás aquí tu casa verdadera". $\mathrm{Si}$, como se ha dicho, Escudero es el poeta de la experiencia (léase experiencia de la sanjuaninidad, como señala Mosert de Flores), entonces, que sean las calles de tierra (como personificación) las que quieran detener 
el camino del yo, parece hablar de un atisbo de sentido en ese mismo camino. Pero la inutilidad de ese llamado se textualiza en los versos siguientes: "Y el ómnibus pasa imperturbable, / se hace el zonzo porque para qué, sabe / no he de hallar lo que busco, sabe/ questoy agarrao por vaya a saber qué" (29).

Como continuación de ese poema, en este volumen sigue "También en tren". Y esa continuación está dada no solo por el conector "también", de referencia extratextual (es decir, que remite a algo que parece no estar en el texto), sino también por la repetición de la metáfora de la vida como viaje, esta vez en tren. Y la tonalidad afectiva, la desesperación ante el sinsentido de la existencia, aparece nuevamente como una pregunta retórica: "Ntonces: / ¿Es mentirme a mí mismo buscar lo que no? / Puede que así sea pero estoy / gastando muchos pasajes en tren / y a veces en ómnibus para no llegar" (31).

$\mathrm{Si}$ en estos poemas predomina el tono desesperado del que no encuentra una certeza o un sentido, en el poema "A cielo abierto", el tono general es totalmente opuesto: el poeta sabe que en el cielo está escrito nuestro destino humano.

Volviendo a Lakoff y Johnson, en cuanto a las metáforas orientacionales, en las que se "organiza un sistema global de conceptos en relación a otros" (1991:50), podemos inferir que, mientras la metáfora del camino apunta a lo terrenal (el "abajo" presente también en esta poesía en el sintagma nominal "campo abierto"), esta metáfora de "a cielo abierto" 3 remite necesariamente al "arriba".

El humor, casi ausente en otros poemas de este mismo volumen, se da en la pregunta del amigo: “Mi amigo dudó: cestá escrito?” y la respuesta

3 Es inevitable leer en esta construcción de "a cielo abierto" y en las condiciones de producción del escritor, una alusión de Escudero a la minería. En efecto, se denomina "minería a cielo abierto" la minería que se desarrolla en la superficie del terreno, a diferencia de la mina subterránea o de perforación. Pero, además, el adjetivo "abierto", es re-significado: como si los secretos de lo espiritual y lo divino hubieran sido descifrados, "abiertos". 
"divina" que el poeta descifra: "En eso un aerolito/ trazó en el cielo una raya de luz/ Casi grité: ¡Está escrito mirá, / ahí el cielo puso la rúbrica!” (37).

\section{Lo inefable: el amor}

Otro de los temas que aparecen en Dicho en mí es el amor. Ejemplos de esta poesía amorosa son: "Crudeza", "Desmoronamiento", "Cueca", "Lo inefable". En estos poemas, predomina el sentimiento de tristeza y nostalgia por lo perdido, lo que no pudo ser.

En "Crudeza", el yo lírico se dirige a un alocutario indeterminado que parece escuchar la confesión del poeta: "Dejame decir esto en la calle desolada / donde va a lo lejos / el recuerdo de lo ya no". Pero en la estrofa siguiente, el poeta repite la estrategia de objetivización de la intimidad que ya hemos analizado: "El hombre nuna esquina / y ella en un taxi adiós adiós yéndose" (51).

De esta manera, la poesía evita, elude la confesión directa, convirtiendo la historia inconclusa en ajena, como si solo así pudiera nombrarse lo que no puede decirse.

Si en este poema no puede nombrarse en primera persona el amor perdido, "Lo inefable" (poema que cierra el libro), hace explícita la imposibilidad de hablar de eso. El campo semántico al que aluden las construcciones y el léxico, van hilando para el lector (como alocutario del poema) esa imposibilidad: "ya no me alcanza para decir tanto", "ya no sirven las palabras", "tartamudeo", "atragantamiento de silencio" (71). Tal vez, como dice Blanchot, el poeta "al haberse privado de sí, al haber renunciado a sí, mantiene, sin embargo, en esa desaparición, la autoridad de un poder, la decisión de callarse, para que en ese silencio tome forma, coherencia y sentido lo que habla sin comienzo ni fin" (Blanchot, 1969: 21).

Crudeza e inefabilidad marcan el tono de la poesía amorosa de este libro, aunque la poesía "Cueca" (cuya disposición espacial y musicalidad repiten el ritmo de este tipo de música) parezca desmentirlo en los dos últimos versos: "en vez de quedarme triste / bailo una cueca y ya está" (67). 


\section{Oro nestas piedras}

"Lo inefable", como se ha dicho, cierra este volumen de poesías del escritor sanjuanino. Que este sea el poema que nos despide de su lectura es una venturosa casualidad o una voluntaria declaración de principios. En la poesía de Escudero, la palabra poética, el amor, la búsqueda de un sentido existencial, están siempre asediados por la presencia de la muerte, ya sea como peligro físico, ya sea como confirmación de la inutilidad de la palabra para decir algo.

Algunas de las metáforas que levantan la arquitectura de estos versos no son nuevas. Pero la originalidad, si se quiere, nace de las cosas cotidianas a las que se las asocia. El canto del pájaro como inspiración se transforma aquí en "bulla de catas", el tránsito de la vida se hace en un ómnibus sabio, la muerte espera la consumación de un matrimonio prometido por el poeta.

No hemos hablado, es cierto, de las distorsiones sintácticas y fonéticas de la escritura de Escudero: apócopes, hipérbaton, repeticiones, elipsis que dejan en suspenso un concepto, son estrategias que acercan la poesía a lo coloquial y a lo oral. Estos recursos propios de su poesía y que caracterizan, de algún modo, su estilo, apuntan, según creemos, a lo que hemos dicho antes: lo trascendental está investido de los ropajes de lo cotidiano.

Nos parece oportuno escuchar de nuevo a Blanchot:

[El verso es] palabra asombrosa. Quien profundiza el verso, escapa del ser como certeza, encuentra la ausencia de los dioses, vive en la intimidad de esta ausencia, se hace responsable asumiendo el riesgo, soportando el favor. Quien profundiza el verso debe renunciar a todo ídolo, debe romper con todo, no tener la verdad por horizonte ni el futuro por morada, porque de ningún modo tiene derecho a la esperanza: al contrario, debe desesperar. Quien profundiza el verso, muere, encuentra su muerte como abismo" (Blanchot, 1969: 32).

Se trata, como diría Escudero, de la utopía vana de encontrar "oro nestas piedras" (Escudero, 2011: 387). 


\title{
II. Jorge Leonidas Escudero, pirquinero de palabras
}

\author{
Existe un tesoro, anoticio \\ porque ando en su búsqueda y deseo \\ compartirlo con vosotros. \\ Me desvive encontrarlo \\ y toda la gracia que le adjudico \\ es su inviolable lejura. \\ Jorge Leonidas Escudero. "Búsqueda arcaica".
}

En esta segunda parte del trabajo nos detendremos en el análisis de las formaciones subjetivas en algunos poemas de Cantos del acechante (1995) con el objetivo de construir una noción del plano afectivo configurado en dichos textos.

El libro está compuesto por treinta y seis poemas que, al igual que en Dicho en mí, abordan especialmente los temas de la inspiración poética, el sentido de la vida, el amor y la muerte.

Abren la lectura unas palabras preliminares a cargo del autor en las que presenta sus intereses, sus objetivos y los medios de los que se vale para alcanzarlos. Alló declara lo siguiente: "Busco lo que se busca desde tiempo inmemorial más allá de las ideas, ser espejo de la Unidad. Tamaña pretensión para tan parcial y efímera conciencia" (Escudero, 2011: 303). Esta idea de ir tras lo inasible se repite en algunos poemas, como "Mirada al centro" y "Búsqueda arcaica". El tono afectivo no es de angustia por la imposibilidad. Por el contrario, se presenta casi como una fatalidad de la que el autor no puede o no quiere prescindir, ya que "Raramente sucede la visión nítida y la palabra justa para comunicarla, pero si ello ocurre me siento gratificado tras los muchos intentos fallidos" (307).

Como en una declaración de principios, el sujeto escritor construye un sujeto lírico con el cual se identifica y de cuya voz se hará responsable. Es por ello que, además de la marca de la primera persona con la que comienza el discurso "Busco", sigue explicando que "No tengo otro objetivo que expresar lo que realmente siento, el vínculo, la sensación de 
integración y decirlo en versos inesperados" (307). Se constituye de esta forma en la voz lírica que intentará el verso inesperado y en el paciente que dará a conocer sus disposiciones afectivas y que narrará "historias propias que son como las del vecino" (307).

Las formaciones sensibles y semántico-referenciales a través de las cuales se propone expresarse también están explicitadas de manera general en este texto introductorio: "Sobre eso escribo en lenguaje rimado y sin querer a veces me desvío del habla común debido a la pasión" (307). La forma que empleará será el verso y procurará mantener un lenguaje coloquial, aunque a veces arrebatado por la pasión, se aparte hacia formas de decir más grandilocuentes. Además, como ya lo citamos más arriba, se dispone a expresarse con versos "inesperados" y a narrar sus propias experiencias. Es decir, que existe una voluntad de expresar con formas nuevas lo conocido y familiar. Por otro lado, la aclaración de que sus textos están conformados por componentes factuales, de la realidad extratextual, determina que la interpretación de los poemas tienda al pacto autobiográfico.

Escudero también expresa cuál es su objetivo: “Compartir. He visto un hermoso atardecer y deseo que lo mires. $Y$ mis montañas. $Y$ la mujer. Cualquier cumbre de amor es fuente de poesía" (307). El último párrafo del texto establece la presencia de un alocutario indeterminado extratextual, que es a quien se dirige la voz lírica. Este alocutario es instaurado a partir del empleo de la segunda persona en el verbo "mires" y, ya dentro del cuerpo principal del libro, a través de la referencia a espacios y personas compartidos entre el sujeto que evoca y el sujeto evocado.

Consideramos que a partir de este discurso introductorio el autor establece y determina un pacto de lectura e imparte instrucciones para que el lector sienta y re-experimente las disposiciones afectivas del sujeto escritor. 


\section{Mirada al centro: recuento de vida, recuento de poemas}

El primer poema del libro lleva el nombre de "Mirada al centro". En él se explicita quién es el acechante al que alude el título. Comienza el texto diciendo: "Acechante de mí, mirar oculto, ver / si llegó el esperado visitante, / el intérprete, ser, dicho mi ser por él" (Escudero, 2011: 308) Se produce aquí una difracción afectiva en la que el yo se desdobla en acechante y acechado. Uno mira al centro del otro, lo interpreta, lo dice. El acechante es el poeta que expresa la actividad introspectiva del hombre, que lo examina desde afuera configurando una visión objetivizada de sus emociones.

A partir de la segunda estrofa, estas emociones van a ser evocadas a través de la intertextualidad, con la alusión a fragmentos de poemas del mismo autor que también forman parte de Cantos del acechante. Y si bien desaparece el desdoblamiento del yo lírico, la objetivización se mantiene, porque el recuento de la vida del hombre es en realidad el recuento de los textos del poeta. Por poner un solo ejemplo, en "Mirada al centro" se leen unos versos -"De repente me duele / un antiguo cementerio de mineros. Los huesos / comidos por la tierra sulfatosa" (308)- que recuerdan pasajes del poema "Arroyo El panteón": "No han de quedar ni sus huesos, la tierra sulfatosa / se come a los difuntos a la par del olvido" (335). La revisión de la obra es también rememoración de la vida: como ya quedó anunciado en el texto introductorio, la voz lírica narra las historias propias y expresa los sentimientos "reales" del hombre.

Una vez reunidos poeta y hombre en la primera persona de los verbos de la segunda estrofa de "Mirada al centro", en este recorrido de vida y obra, la voz lírica experimenta una revelación. En la última estrofa, el recuento de recuerdos factuales y textuales concluye en el reconocimiento del amor, la vida y la muerte como elementos centrales de la existencia del hombre y de la creación del poeta: "Es entonces amor que se me canta, / Lo que el mundo hace y la muerte desteje" (308).

El final de la última estrofa presenta un desdoblamiento del sujeto paciente entre un yo y un Espíritu que es el que efectivamente puede llegar a la esencia del ser y expresarla: "Se me alcanza / que toda esta inquietud 
es el Espíritu / que baja al centro de mi ser y habla" (308). Este Espíritu con mayúsculas es esa Unidad que anuncia estar buscando desde la introducción, en la que ya aparece el desdoblamiento cuando se propone "mirar el objeto y al mismo tiempo mi centro para ver si veo más allá de las distorsiones" (307). Pareciera entonces que esta mirada al centro y el recuento de vida y obra que constituyen este poema, serían un acceso para que tanto la voz lírica como el sujeto escritor alcancen "la visión nítida y la palabra para comunicarla" (307).

\section{"Leña" y "Acate": la asunción de la verdad}

"Leña" y "Acate" toman respectivamente los temas del amor y de la muerte. La formación subjetiva en ambos se da de manera semejante. Es significativo que para estos tópicos que impactan directamente el plano afectivo, el sujeto escritor haya elegido la difracción. Se repite el desdoblamiento que acentúa el grado de objetivización de las emociones del yo, con la presencia de una segunda persona a la que la voz lírica constituye en alocutario y paciente. Es, a su vez, un sujeto paciente que se identifica con el sujeto escritor.

La visión que en ambos poemas tiene el yo del tú es de una sonrisa irónica y amarga. El tono afectivo que predomina es el de la impotencia ante la vejez. En el caso de "Leña", esa impotencia se vuelve angustia por la presunción de que resulta ridículo que un hombre que es como "un seco pedazo de leña" (313) aspire al amor. En este texto, la voz lírica se presenta resignada y le informa al paciente acerca de su "verdadera" condición. Lo insta a reconocer el paso del tiempo y la pérdida definitiva de los sueños y las posibilidades de amar y ser amado.

Por su parte, en "Acate" el yo apela a un usted a quien exige la aceptación de su cercanía a la muerte. Creemos, sin embargo, que la difracción afectiva parece más profundizada que en "Leña", porque al parecer, la voz lírica se propone llamar al orden y hacer que se resigne un tú que está desacatado y no acepta su "verdadera" situación, es decir, la escasez de vida que le resta. 
En suma, la voz lírica se propone asumir la "verdadera" condición de ese yo-tú como sujeto con un cuerpo en relación con el mundo, consigo mismo y con los otros. Pretende revelar(se) una "verdad" dolorosa pero que presenta como incuestionable. Porque, en su afán de llegar a la percepción nítida de la realidad o de lo esencial o de la Unidad, la poesía se vuelve a convertir en el medio capaz de develar sin concesiones.

\section{La búsqueda infinita}

Como el pirquinero que busca oro entre las montañas sin más empeño que el propio, Jorge Leonidas Escudero explora las palabras para extraer ese Sentido en mayúsculas que lo acerque a la verdad, al centro, a la Unidad sin distorsiones donde puede asirse lo inasible y pronunciarse lo inefable. Ese tesoro cuya mayor gracia es "su inviolable lejura" (339). Búsqueda infinita que como tal se alimenta del placer, la angustia, la pulsión de ser llevada a cabo. Y de la promesa, débil y lejana, de alguna vez alcanzar lo deseado: la verdad. Porque la búsqueda es el sentido de la vida, lo que justifica el sacrificio. Ansia que es ella misma riqueza y posesión. Porque "La gracia de nosotros es ir en pos de andar, / golpear con la cabeza el horizonte / a ver si gana felicidá" (339).

\section{Conclusiones}

La confrontación entre los dos libros de poesías de Escudero permite intuir en ellos algo que es del orden de la vida humana: mientras que en Cantos del acechante (de escritura más temprana) conserva todavía la esperanza de encontrar la palabra que diga, Dicho en mí es la desesperación, la certeza de la incerteza de hallarla.

Hemos querido, de alguna manera, seguir la senda del hombre-poeta en dos etapas diferentes de su vida: la intimidad de una ausencia.

Expresar, decir los sentimientos "reales" de su experiencia vital, deviene en el libro de su vejez en el oficio de catitero, de perseguidor de sueños utópicos que a veces, solo a veces, alcanza a clavar con alfileres unas pocas moscas negras. 


\section{Referencias}

Blanchot, Maurice (1969). El espacio literario. Buenos Aires: Paidós.

Escudero, Jorge Leonidas (1978). Le dije y me dijo. San Juan: Spae.

Escudero, Jorge Leonidas (2008). Dicho en mí. Buenos Aires: Cantos en Danza.

Escudero, Jorge Leonidas (2011). Poesía completa. Buenos Aires: Cantos en Danza.

Lakoff, George y Mark Johnson (1991). Metáforas de la vida cotidiana. Madrid: Cátedra.

Pérez Rioja, José Antonio (1997). Diccionario de símbolos y mitos. Madrid: Tecnos.

Robledo, María Esther (2010). "Jorge Leonidas Escudero". Entretejerpalabras.blogspot.com, 11 jul. http://entretejerpalabras.blogspot.com/2010_07_11_archive.html

Urrutia, Álvaro (2008). "Jorge Leonidas Escudero: un poeta para comprendernos". Porlahuelladeldiablo.blogspot.com, 16 sept.

http://porlahuelladeldiablo.blogspot.com/2008/09/jorge-leonidas-escudero-un-poetapara.html

Zonana, Víctor Gustavo (2008). "La conformación subjetiva en el poema: variables, niveles y perspectivas de análisis". Signo \& Seña, n. 19. 33-66. Disponible en: http://revistascientificas.filo.uba.ar/index.php/sys/article/view/5760 